\title{
Effect of Probabilistic Pattern on System Voltage Stability in Decentralized Hybrid Power System
}

\author{
Nitin Kumar Saxena, Ashwani Kumar \\ National Institute of Technology, Kurukshetra, India \\ Email: nitinsaxena.iitd@gmail.com, ashwa_ks@yahoo.co.in
}

Received 18 August 2015; accepted 7 November 2015; published 10 November 2015

Copyright (C 2015 by authors and Scientific Research Publishing Inc.

This work is licensed under the Creative Commons Attribution International License (CC BY). http://creativecommons.org/licenses/by/4.0/

(c) (i) Open Access

\section{Abstract}

This paper presents an proportional integral (PI) based voltage-reactive power control for wind diesel based decentralized hybrid power system with wide range of disturbances to demonstrate the compensation effect on system with intelligent tuning methods such as genetic algorithm (GA), artificial neural network (ANN) and adaptive neuro fuzzy inference system (ANFIS). The effect of probabilistic load and/or input power pattern is introduced which is incorporated in MATLAB simulink model developed for the study of decentralized hybrid power system. Results show how tuning method becomes important with high percentage of probabilistic pattern in system. Testing of all tuning methods shows that GA, ANN and ANFIS can preserve optimal performances over wide range of disturbances with superiority to GA in terms of settling time using Integral of Square of Errors (ISE) criterion as fitness function.

\section{Keywords}

Reactive Power Control, Hybrid Power Systems, Genetic Algorithms, Load, Artificial Neural Network, Adaptive Neuro Fuzzy Interface System

\section{Introduction}

Over 400 million people in India, including $47.5 \%$ of those living in India's rural areas, still had no access to electricity [1]. Government of India is promoting use of decentralized distributed generating units through various schemes [2]. In recent years, the production of clean energy (renewable ones) by private investors is encouraged [3]. In wind diesel based power system, normally self excited induction generator is used for fetching power through wind while synchronous generator is used for fetching power through diesel operated genset. The 
main drawback of using induction generator is that it demands reactive power for its operation [4] [5]. The reactive power is also required in system for stabilizing the voltage response due to the changes in load and input power demand. This demand is fulfilled by fast acting dynamic device so that the system may attain its steady state in least time. STATCOM operation as dynamic reactive power compensator is most popular in such studies. STATCOM operates to release/absorb reactive power as per the system requirement by controlling firing angle in STATCOM. STATCOM consists of three blocks namely PI controller, transport lag and phase sequence delay [6]. By proper PI constants tuning, system voltage may be stabilized rapidly during disturbances in the system.

The control signal provided by PI controller is dependent upon two terms and is given by;

$$
U(s)=\left(K_{P}+\frac{K_{I}}{s}\right) E(s)
$$

$U(s)$ is control signal and $E(s)$ is error signal, which is the difference between the reference signal $R(s)$ and system output $Y(s) . K_{P}$ and $K_{I}$ are the proportional and integral gains respectively. It is necessary to automatically tune PI parameters for obtaining satisfactory response. Therefore, researchers are continuously trying to explore the best method in searching optimum PI parameters [7].

Genetic Algorithm is a soft computing technique which is used for optimization of PI parameters of STATCOM. Despite excellence performance by GA in searching globally acceptable optimum solution of PI controller constants, some researchers have pointed out deficiencies in GA performance viz. poor premature convergence, loss of best solution found and no absolute assurance that a genetic algorithm will find a global optimum. In recent years, Fuzzy Inference Systems (FISs) and Artificial Neural Networks (ANNs) have attracted considerable attention as candidates for novel computational systems because of the variety of the advantages that they offer over conventional computational systems [8]. The ANFIS combines the advantages of FLCs and ANNCs, avoiding their problems on the other hand.

The biggest challenge is the uncertainty associated with wind power and load demand. In order to deal with these load uncertainties in load flow problem, many probabilistic load flow methods have been proposed in the literature [9]. In previous studies static load is used as deterministic load model that assumes that power injections, power consumptions, network parameters and topology are specified and do not change during the computation [10]-[12]. The author has investigated the role of the composite load which includes participation of static and dynamic load simultaneously.

In decentralized power system, probabilistic load model (PLM) is considered using random variables as uniform PDF, Weibull PDF, normal PDF, lognormal PDF and beta PDF [9] [13] [14].

Hence, this paper contribution may be summarized as: i) effect on the performance of dynamic compensation using wide range of probabilistic pattern in composite load model and input wind power; ii) estimation of tuning parameters for STATCOM using GA, ANN and ANFIS based soft-tuning methods.

\section{Voltage-Reactive Powers Balance Equation}

Promotional schemes of Government of India are continuously motivating to private investors for installing decentralized hybrid power systems like Wind diesel based system shown in Figure 1. The sudden change in load demand and input power causes a voltage deviation, to stabilize these changes synchronous generator and STATCOM may releases extra reactive power. The reactive power equations for all components and power balance equations as in Equation (2) evolved in decentralized hybrid power systems are well established and documented in [12] [15] [16].

$$
\Delta V(s)=\frac{1}{D_{v}+s \frac{V}{\omega X_{m}}}\left[\Delta Q_{S G}(s)+\Delta Q_{S T}(s)-Q_{I G}(s)-Q_{L}(s)\right]
$$

Synchronous generator and STATCOM generate while induction generator and load demand reactive power. In [17], author has given full description about modeling and voltage response using MATLAB. In this work, author is interested to analyze the compensating behaviour of STATCOM with soft tuning methods and probabilistic load patterns in wind input and load power disturbances.

From Equation (3), incremental change in STATCOM reactive power can be expressed as [18]-[20]. 


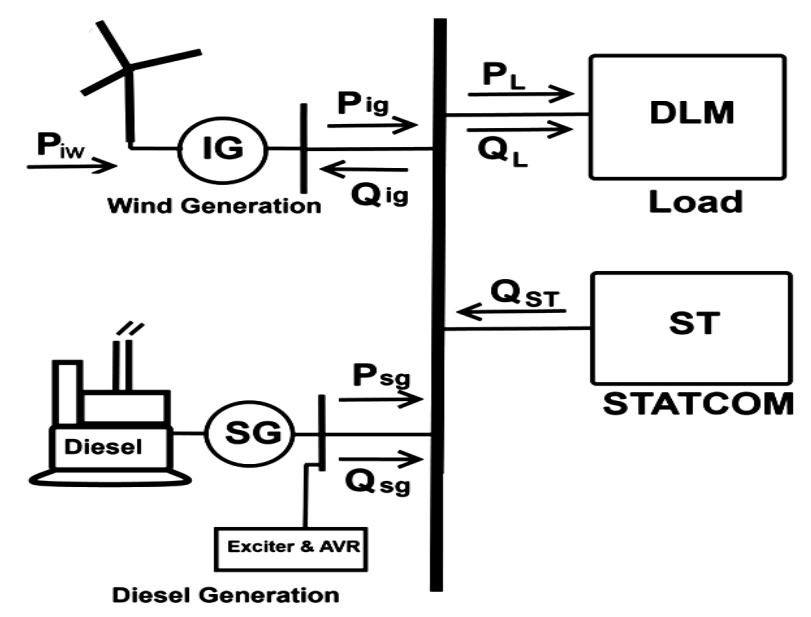

Figure 1. Block representation for decentralized hybrid power system.

$$
\Delta Q_{\text {STAтсом }}(s)=k V_{d c} V B \operatorname{Sin} \alpha \Delta \alpha(s)-k V_{d c} B \operatorname{Cos} \alpha \Delta V(s)
$$

In Figure 2 gain G1 and G2 denotes multiplier of Equation (3); STATCOM action is controlled by adjusting firing angle with the help of $K_{P}$ and $K_{I}$. The design criterion is based on minimization of integral of square error (ISE) performance criterion in all tuning methods.

\section{Probabilistic Load Disturbances}

It has been concluded that power system voltage stability behaviour and choice of compensation techniques significantly depends on selection of the load model and its parameters [21] [22]. In order to effectively analyze the dynamics of decentralized hybrid power system, loads need to be regarded along with the generators in a transient stability analysis. With a poor load model we would need to operate the system with a higher safety margin. Many papers have been published about composite load modelling which includes the composite load as a combination of static and dynamic load model [23]-[25].

The simulation study of the system requires a transfer function, $D_{v}$ for load reactive power change with voltage change as depicted in Equation (2). $D_{v}$ for composite load model can be evaluated by adding the transfer functions of static and dynamic load model.

$$
\left(D_{v}\right)_{\text {composite }}=\left(D_{v}\right)_{\text {static }}+\left(D_{v}\right)_{\text {dynamic }}
$$

These static and dynamic load model transfer functions are investigated in detail in [26]. The static load is represented by an exponential function of bus voltage magnitude as given in Equation (5). The reactive power expression for static load model is;

$$
Q_{\text {static }}=Q_{\text {static }}^{0}\left(\frac{V}{V^{0}}\right)^{n_{q}}
$$

The transfer function of reactive power change to voltage change $D_{v}$ for static load model is given in Equation (6). The value of load power factor is considered 0.9 lagging and value of $n_{q}$ is used 3 for this paper [24] [25].

$$
\left(D_{v}\right)_{\text {static }}=n_{q} \frac{Q^{0}}{V^{0}}
$$

The knowledge of induction motor responses is essential for dynamic load modelling. An algorithm to achieve $D_{v}$ for $5^{\text {th }}$ order model of induction motor as dynamic load model is given below:

1) Collection of manufacturer data.

2) Identification of equivalent circuit parameters of induction motor.

3) Estimation of Induction motor responses. 


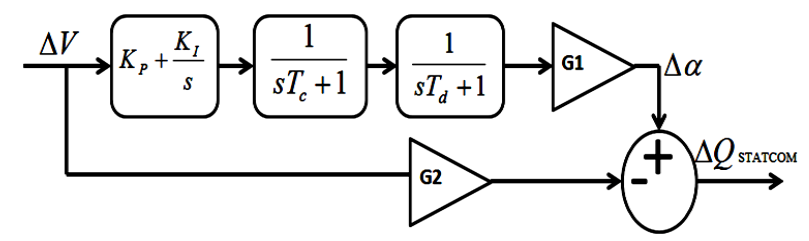

Figure 2. Block representation of STATCOM.

4) State space modelling of induction motor.

5) Configuration of transfer function of reactive power change to voltage change.

Finally state space model of dynamic load is used to evaluate $D_{v}$. To understand the behaviour of STATCOM for reactive power compensation in system a $10 \%$ step disturbance is given in load demand and input power. The system is much affected by the uncertainties produced by the load reactive power demand and wind input real power at the time of its operation. To analyse the effect of uncertainties, a probabilistic pattern is introduced with these step disturbances. To check the viability of the system compensation in presences of uncertainties, three patterns of disturbances are studied for the simulink model:

Pattern 1: $10 \%$ step disturbances in load and input power;

Pattern 2: Introducing $1 \%$ probabilistic pattern with $10 \%$ step disturbances in load and input power;

Pattern 3: Introducing 10\% probabilistic pattern with $10 \%$ step disturbances in load and input power.

Figure 3 and Figure 4 show these probabilistic patterns in wind input real power and load reactive power demand. Probabilistic pattern requires state variable inputs to be modelled by a probabilistic density function (PDF). Wind speed and load demand are modelled as random variables (RVs) due to their random behavior using uniform probability distribution.

\section{Tuning of Statcom Controller Gain}

Figure 3 and Figure 4 signals are given to MATLAB based simulink model shown in Figure 5 which is designed including subsystem of each component for the transient response study of decentralized hybrid power system. The voltage responses for these three predefined patterns of disturbances are plotted after tuning of PI controllers. In parameter optimization problems the structure of the controller is assumed and an attempt is made to determine the optimum setting of the controller parameters. Constants of proportional and integral gain controller are tuned first by using performance index based conventional PI tuning method.

The performance index used in the parameter optimization is based on the integral square error ISE criterion. If $e^{2}(t)$ is the square of the error signal produced as the voltage output. For the discrete data this integration can be transferred as, if $E_{i}(t)=e^{2}(t)$.

$$
\mathrm{ISE}=\sum_{t=1}^{k-1} E_{i}(t) \times t_{i+1}
$$

The value of proportional and integral constant $\left(K_{P}\right.$ and $\left.K_{I}\right)$ can be selected for minimum value of ISE. To tune parameters with genetic algorithm, value of proportional and integral constant $\left(K_{P}\right.$ and $\left.K_{I}\right)$ evaluated for conventional tuning method is used as a reference value.

Like any other optimization algorithm GA starts with defining the optimization variables, the fitness function and the fitness. It ends by testing for convergence. The general steps implemented when using GAs are:

1) Generate a random initial population;

2) Create the new population by applying the selection and reproduction operators to select pairs of strings. The number of pairs is the population size divided by two, so the population size will remain constant between generations;

3) Apply the crossover operator to the pairs of the strings of the new population;

4) Apply the mutation operator to each string in the new population;

5) Replace the old population with the newly created population;

6) Copy the best-fitted individuals to the newly created population to warrantee evolution;

7) If the number of iterations is less than the maximum go to step two, else stop OR If the fitness of the best result does not get better over certain number of iteration, then stop.

Adaptive control is an attempt to redesign the controller according to its performance and to tune its parameters automatically. Both ANN and ANFIS can be utilized to fine tune the PI controller parameters to be an adap- 


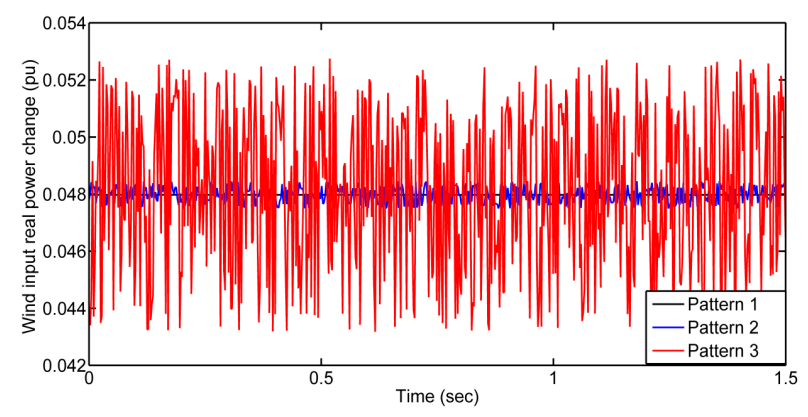

Figure 3. Patterns for wind input power disturbances.

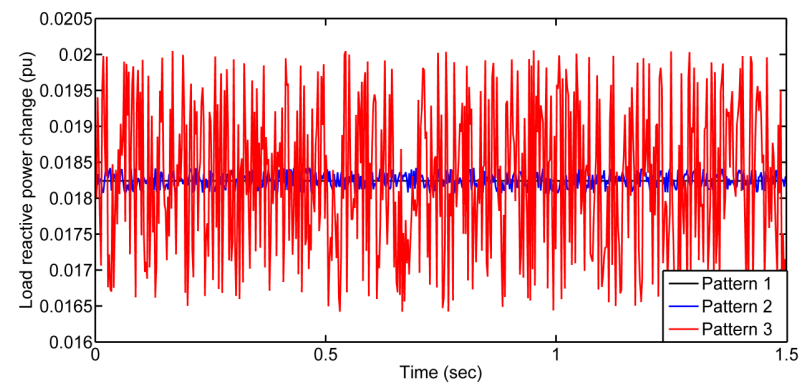

Figure 4. Patterns for load demand disturbances.

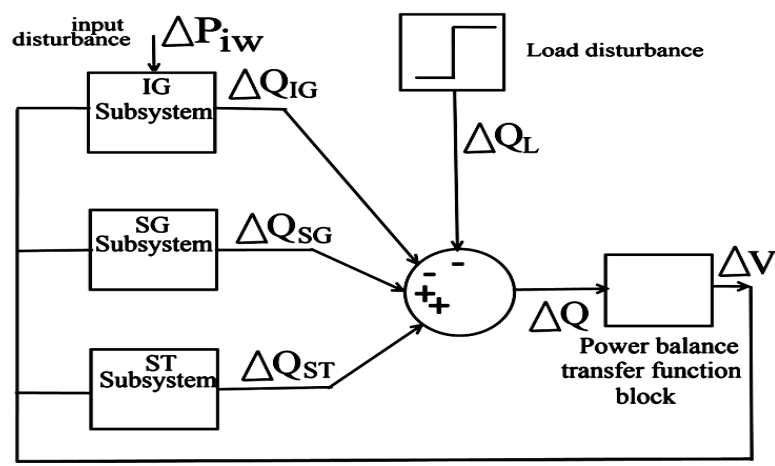

Figure 5. Simulink block diagram for decentralized hybrid power system.

tive PID controller. Unlike other classical control methods, these methods do not require exact mathematical model of the system [27].

The training process of ANN model has been performed using the ANN toolbox of MATLAB. The multi-layer feed-forward network used in this work was trained using the back propagation (BP) paradigm developed.

The ANFIS combines the advantages of fuzzy logic controllers and artificial neural network controllers, avoiding their problems on the other hand [28]-[32].

In this paper, simulation results reveals that intelligent methods provide better performance than the conventional method in terms of various performance specifications. In this paper, the controller tuned by the various methods has been used for concentration control of a STATCOM. The intelligent methods provide better performance in terms of various performance specifications than the conventional method while the steady state error remains same at zero.

\section{Performance Evaluation of System}

This study is compared with three different disturbance patterns as given in Figure 3 and Figure 4. STATCOM 
controller constants are tuned by four different methods namely; conventional tuning method, GA based tuning method, ANN based tuning method and ANFIS based tuning method. The procedure for getting gain constants through conventional tuning method and GA based tuning is described in detail in last section.

For ANN based tuning, three layers neural network (having an input layer with one input representing the voltage change, a hidden layer including 20 neurons and an output layer for the two control parameters $K_{P}$ and $\mathrm{K}_{\mathrm{I}}$ ) have been used, together with supervised training via a back-propagation technique. It should be mentioned that all Neural Networks are developed using NFTOOL Toolbox of MATLAB.

For ANFIS based tuning, a single-input three-output ANFIS is designed. For initializing the fuzzy system, a FIS file is trained with 100 epochs for the study. The number of MFs for the input variables is 3 . The gbellmf membership function used for input variables and output membership function type is a linear type. It is worth noting that three ANFIS models are designed for the two control parameters $K_{P}$ and $K_{I}$ due to a limitation of ANFIS toolbox to have only one output per ANFIS. The results for $K_{P}$ and $K_{I}$ are tabulated in Table 1 for all four tuning methods using ISE criterion.

Voltage performances for three predefined disturbances pattern in input wind and load demand are compared and plotted as shown in Figures 6-9. As Figure 6 depicts that the results of conventional tuning method are out of context. The results of intelligent tuning methods (in terms of settling time, voltage dip, voltage rise and rise time) are compared in Tables 2-4.

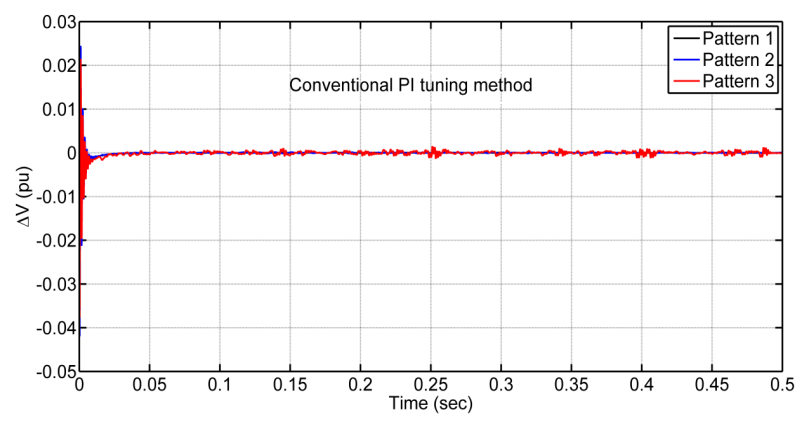

Figure 6. Voltage comparison with conventional PI tuning.

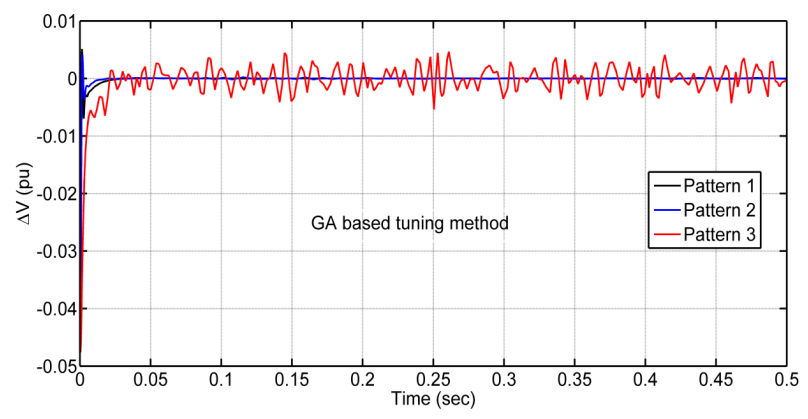

Figure 7. Voltage comparison with GA based tuning.

Table 1. Comparative study for STATCOM gain constants.

\begin{tabular}{cccccc}
\hline & Values & \multicolumn{3}{c}{ Tuning methods } \\
\cline { 3 - 6 } & & Conventional PI & GA & ANN & ANFIS \\
\hline \multirow{2}{*}{ Pattern 1 } & $K_{P}$ & 34.3 & 12.06 & 11.7 & 12.7 \\
& $K_{I}$ & 3990 & 2498 & 2511 & 2470 \\
Pattern 2 & $K_{P}$ & 34.3 & 8.92 & 13.4 & 13.1 \\
& $K_{I}$ & 4152 & 3247 & 4237 & 4210 \\
Pattern 3 & $K_{P}$ & 35 & 1.44 & 4.4 & 4.04 \\
& $K_{I}$ & 3020 & 758 & 987 & 969 \\
\hline
\end{tabular}




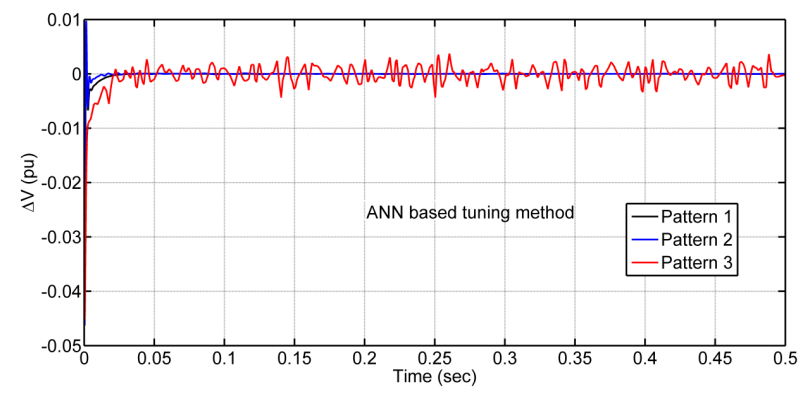

Figure 8. Voltage comparison with ANN based tuning.

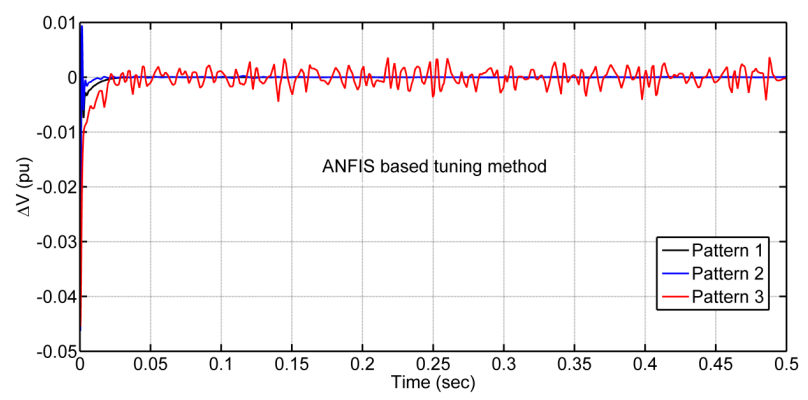

Figure 9. Voltage comparison with ANFIS based tuning.

Table 2. Transient study for voltage response using GA based tuning.

\begin{tabular}{cccc}
\hline & Pattern 1 & Pattern 2 & Pattern 3 \\
\hline $\mathrm{t}_{\mathrm{s}}(\mathrm{sec})$ & 0.0136 & 0.0077 & - \\
$\mathrm{V}_{\text {dip }}(\mathrm{pu})$ & -0.0462 & -0.0476 & 0.0474 \\
$\mathrm{~V}_{\text {rise }}(\mathrm{pu})$ & 0.0051 & 0.0042 & 0.0048 \\
$\mathrm{t}_{\mathrm{r}}(\mathrm{sec})$ & $0.0011 \times 10^{-7}$ & $0.1700 \times 10^{-6}$ & $0.2887 \times 10^{-5}$ \\
\hline
\end{tabular}

Table 3. Transient study for voltage response using ANN based tuning.

\begin{tabular}{cccc}
\hline & Pattern 1 & Pattern 2 & Pattern 3 \\
\hline $\mathrm{t}_{\mathrm{s}}(\mathrm{sec})$ & 0.0134 & 0.0075 & - \\
$\mathrm{V}_{\text {dip }}(\mathrm{pu})$ & -0.0463 & -0.0462 & -0.0452 \\
$\mathrm{~V}_{\text {rise }}(\mathrm{pu})$ & 0.0048 & 0.0097 & 0.0038 \\
$\mathrm{t}_{\mathrm{r}}(\mathrm{sec})$ & $0.0037 \times 10^{-7}$ & $0.0705 \times 10^{-6}$ & $0.1395 \times 10^{-5}$ \\
\hline
\end{tabular}

Table 4. Transient study for voltage response using ANFIS based tuning.

\begin{tabular}{cccc}
\hline & Pattern 1 & Pattern 2 & Pattern 3 \\
\hline $\mathrm{t}_{\mathrm{s}}(\mathrm{sec})$ & 0.0142 & 0.0074 & - \\
$\mathrm{V}_{\text {dip }}(\mathrm{pu})$ & -0.0460 & -0.0463 & -0.0454 \\
$\mathrm{~V}_{\text {rise }}(\mathrm{pu})$ & 0.0057 & 0.0095 & 0.0041 \\
$\mathrm{t}_{\mathrm{r}}(\mathrm{sec})$ & $0.0092 \times 10^{-7}$ & $0.8059 \times 10^{-6}$ & $0.1590 \times 10^{-5}$ \\
\hline
\end{tabular}

GA, ANN and ANFIS tuning based methods give system voltage variations within a certain acceptable band. It can also be revealed that ANFIS gives better performance than ANN and GA in terms of settling time. With $10 \%$ probabilistic disturbances system is not stabilizing but due to intelligent tuning especially with ANFIS 
method, system voltage response approaches closure to steady state value. System first peak overshoot also decreases with ANFIS.

\section{Conclusion}

This paper presents a design methodology based on ANN and ANFIS for an adaptive PI voltage reactive powers control. A wide range of disturbances are considered to demonstrate the effect of system with different tuning methods. GA is employed to obtain the parameters of the PI controller yielding optimal responses. The data obtained through GA are used to train both ANN and ANFIS agent, which give the optimal controller parameters within the specified range. Both ANN testing and ANFIS testing denote notable effectiveness in learning and mapping the system characteristics. The system voltage responses also denote the effectiveness of intelligent controller over conventional controllers especially in presence of highly fluctuating disturbances.

\section{References}

[1] Indian Member Committee (2007) Transmission and Distribution in India. A Report by POWER GRID and World Energy Council.

[2] Government of India (2013) Guidelines for Village Electrification through Decentralized Distributed Generation (DDG) under Rajiv Gandhi Grameen Vidyutikaran Yojana in the XI Plan-Scheme of Rural Electricity Infrastructure and Household Electrification. A Report by Ministry of Power.

[3] Soroudi, A., Aien, M. and Ehsan, M. (2012) A Probabilistic Modeling of Photo Voltaic Modules and Wind Power Generation Impact on Distribution Networks. IEEE Systems Journal, 6, 254-259. http://dx.doi.org/10.1109/JSYST.2011.2162994

[4] Hunter, R. and Elliot, G. (1994) Wind-Diesel Systems, A Guide to the Technology and Its Implementation. Cambridge University Press, Cambridge.

[5] Bansal, R.C. (2005) Three Phase Self-Excited Induction Generators: An Overview. IEEE Transactions on Energy Conversion, 20, 292-299. http://dx.doi.org/10.1109/TEC.2004.842395

[6] Sharma, P., Sulkowski, W. and Hoff, B. (2013) Dynamic Stability Study of an Isolated Wind-Diesel Hybrid Power System with Wind Power Generation Using IG, PMIG and PMSG: A Comparison. Electrical Power and Energy Systems, 53, 857-866. http://dx.doi.org/10.1016/j.ijepes.2013.06.014

[7] Chopra, V., Singla, S.K. and Dewan, L. (2014) Comparative Analysis of Tuning a PID Controller Using Intelligent Methods. Acta Polytechnica Hungarica, 11, 235-249.

[8] Jaiswal, M. and Phadnis, M. (2013) Speed Control of DC Motor Using Genetic Algorithm Based PID Controller. International Journal of Advanced Research in Computer Science and Software Engineering, 3, 247-253.

[9] Briceno Vicente, W.C., Caire, R. and Hadjsaid, N. (2012) Probabilistic Load Flow for Voltage Assessment in Radial Systems with Wind Power. Electric Power and Energy System, 41, 27-33. http://dx.doi.org/10.1016/j.ijepes.2012.02.014

[10] Bansal, R.C., Bhatti, T.S. and Kothari, D.P. (2004) A Novel Mathematical Modelling of Induction Generator for Reactive Power Control of Isolated Hybrid Power Systems. International Journal of Modelling and Simulation, 24, 1-7. http://dx.doi.org/10.2316/Journal.205.2004.1.205-4068

[11] Mohanty, A., Soumya, R., Kishor, M.N. and Ray, P.K. (2013) Self Tuned Fuzzy-Pi Based Reactive Power Compensation in Wind-Diesel Hybrid System. Proceedings of the International Conference on Circuits, Power and Computing Technologies, Nagercoil, 20-21 March 2013, 362-367.

[12] Banerjee, A., Mukherjee, V. and Ghoshal, S.P. (2013) Modeling and Seeker Optimization Based Simulation for Intelligent Reactive Power Control of an Isolated Hybrid Power System. Swarm and Evolutionary Computation, 13, 85-100. http://dx.doi.org/10.1016/j.swevo.2013.05.003

[13] Aien, M., Ramezani, R. and Ghavami, S.M. (2011) Probabilistic Load Flow Considering Wind Generation Uncertainty. Technology \& Applied Science Research, 1, 126-132.

[14] Reza, M., Papaefthymiou, G. and Schavemaker, P.H. (2006) An Example of Utilizing Stochastic Approach for Investigating Network Constraints (Congestions) on Horizontally Operated Power Systems with Distributed Generation. Jurnal Teknik Elektro, 6, 79-86.

[15] Bansal, R.C., Bhatti, T.S. and Kumar, V. (2007) Reactive Power Control of Autonomous Wind Diesel Hybrid Power Systems Using ANN. Proceedings of IPEC, Singapore, 3-6 December 2007, 982-987.

[16] Saxena, N. and Kumar, A. (2010) Load Modeling Interaction on Hybrid Power System Using STATCOM. Proceedings of INDICON 2010, Kolkata, 17-19 December 2010, 1-4. http://dx.doi.org/10.1109/indcon.2010.5712691 
[17] Saxena, N.K. and Kumar, A. (2015) Analytical Comparison of Static and Dynamic Reactive Power Compensation in Isolated Wind Diesel System Using Dynamic Load Interaction Model. Electric Power Components and Systems, 53, 508-519. http://dx.doi.org/10.1080/15325008.2014.993777

[18] Kouadri, B. and Tahir, Y. (2008) Power Flow and Transient Stability Modeling of a 12-Pulse STATCOM. Journal of Cybernetic and Informatics, 7, 9-25.

[19] Canizares, C.A. (2003) STATCOM Modeling for Voltage and Angle Stability Studies. Electrical Power \& Energy Systems, 25, 1-20. http://dx.doi.org/10.1016/S0142-0615(02)00125-4

[20] Sharma, P., Saxena, N.K. and Bhatti, T.S. (2009) Study of Autonomous Hybrid Power System Using SVC and STATCOM. Proceedings of ICPS 2009, Kharagpur, 27-29 December 2009, 1-5. http://dx.doi.org/10.1109/icpws.2009.5442770

[21] Stojanovi, D.P., Korunovi, L.M. and Milanovi, J.V. (2008) Dynamic Load Modelling Based on Measurements in Medium Voltage Distribution Network. Electric Power Systems Research, 78, 228-238. http://dx.doi.org/10.1016/i.epsr.2007.02.003

[22] Shahnia, F., Ritwik, M., Arindam, G., Gerard, L. and Firuz, Z. (2010) Operation and Control of a Hybrid Microgrid Containing Unbalanced and Nonlinear Loads. Electric Power Systems Research, 80, 954-965.

[23] Tania, P. (2009) Composite Load Model Decomposition: Induction Motor Contribution. Dissertation for the Doctoral Degree, Faculty of Built Environment and Engineering, School of Engineering Systems, Queensland University of Technology, Brisbane.

[24] Kim, B.H., Kim, H. and Lee, B. (2012) Parameter Estimation for the Composite Load Model. Journal of International Council on Electrical Engineering, 2, 215-218. http://dx.doi.org/10.5370/JICEE.2012.2.2.215

[25] Choi, B.K., Chiang, H.-D., Li, Y.H., Chen, Y.-T., Huang, D.-H. and Lauby, M.G. (2006) Development of Composite Load Models of Power Systems Using On-Line Measurement Data. Journal of Electrical Engineering \& Technology, 1, 161-169. http://dx.doi.org/10.5370/JEET.2006.1.2.161

[26] Nitin, S. and Ashwani, K. (2014) Reactive Power Compensation of an Isolated Hybrid Power System with Load Interaction Using ANFIS Tuned STATCOM. Frontiers in Energy, 8, 261-268. http://dx.doi.org/10.1007/s11708-014-0298-6

[27] Mote, T.P. and Lokhande, S.D. (2012) Temperature Control System Using ANFIS. International Journal of Soft Computing and Engineering, 2, 156-161.

[28] Dastranj, M.R., Ebrahimi, E., Changizi, N. and Sameni, E. (2011) Control DC Motor Speed with Adaptive Neuro Fuzzy Control (ANFIS). Australian Journal of Basic and Applied Sciences, 5, 1499-1504.

[29] Kusagur, A., Kodad, S.F. and Sankar Ram, B.V. (2010) Modeling, Design \& Simulation of an Adaptive Neuro-Fuzzy Inference System (ANFIS) for Speed Control of Induction Motor. International Journal of Computers and Applications, 6, 29-44. http://dx.doi.org/10.5120/1123-1472

[30] Mossad, M.I. and Salem, F. (2014) LFC Based Adaptive PID Controller Using ANN and ANFIS Techniques. Journal of Electrical Systems and Information Technology, 1, 212-221.

[31] Dastranj, M.R., Ebrahimi, E., Changizi, N. and Sameni, E. (2011) Control DC Motor Speed with Adaptive Neuro Fuzzy Control (ANFIS). Australian Journal of Basic and Applied Sciences, 5, 1499-1504.

[32] Kusagur, A., Kodad, S.F. and Sankar Ram, B.V. (2010) Modeling, Design \& Simulation of an Adaptive Neuro-Fuzzy Inference System (ANFIS) for Speed Control of Induction Motor. International Journal of Computers and Applications, 6, 29-44. http://dx.doi.org/10.5120/1123-1472 


\section{Appendix}

System capacity, voltage and ratings of the system components used in this simulation study of wind diesel based isolated hybrid power system are as following:

Base power $=250 \mathrm{~kW}$;

Base voltage $=400 \mathrm{~V}$;

$\mathrm{SG}$ rating $=100 \mathrm{~kW}$

IG rating $=150 \mathrm{~kW}$;

Static load rating $=200 \mathrm{~kW}$;

Dynamic load rating $=50 \mathrm{~kW}$;

Composite load rating $=250 \mathrm{~kW}$.

\section{Nomenclature}

$\Delta Q_{S G}$ and $\Delta Q_{S T}$ : Incremental change in reactive power generated by Synchronous Generator and STATCOM; $\Delta Q_{I G}$ and $\Delta Q_{L}$ : Incremental change in reactive power absorbed by Induction Generator and load;

$V:$ Load terminal voltage;

$\Delta V$ : Incremental change in load voltage due to load and/or input disturbances;

$X_{m}$ : Magnetising reactance referred to stator side in IG;

$D_{v}$ : Transfer function for reactive power change with voltage change;

$k$ : STATCOM coefficient depending on the number of pulse in converter;

$V_{d c}:$ STACOM de voltage;

$B$ : Susceptance of the STATCOM;

$\alpha$ : Firing angle of the STATCOM. 